\title{
Volume gain of periaqueductal gray in medication-overuse headache
}

\author{
Zhiye Chen ${ }^{1,2}$, Xiaoyan Chen², Mengqi Liu', Shuangfeng Liu', Lin Ma' ${ }^{1 *}$ and Shengyuan $\mathrm{Yu}^{2^{*}}$
}

\begin{abstract}
Background: Periaqueductal gray (PAG) is a substantial descending pain modulatory center, and previous voxel-based morphometry study confirmed the clusters with increased volume in PAG region in medication-overuse headache $(\mathrm{MOH})$. The aim of this study is to investigate altered PAG volume in $\mathrm{MOH}$ using an automated PAG segment method to measure the true PAG volume.

Methods: High resolution three-dimensional T1-weighted fast spoiled gradient recalled echo MR images were obtained from 22 patients with MOH and 22 normal controls (NC). PAG template was created based on ICBM 152 gray template, and the individual PAG was generated by applying the deformation field from structural image segment to the PAG template, and individual PAG volume was calculated.

Results: There was a significant increased volume of PAG in $\mathrm{MOH}(0.366 \pm 0.005 \mathrm{ml})$ than that in NC $(0.341 \pm 0$. $005 \mathrm{ml})(P<0.05)$. There was no significant correlation between the PAG volume and the clinical variables in $\mathrm{MOH}$ patients $(P>0.05)$. The area of receiver operating characteristic (ROC) curve was 0.845 , and the cut-off of PAG volume was $0.341 \mathrm{ml}$ with sensitivity $95.5 \%$ and specificity $63.6 \%$.

Conclusion: The present study demonstrated that the PAG volume gain was confirmed in $\mathrm{MOH}$ patients, and the automated individual PAG volume measure may be considered as a simple and effective imaging biomarker in $\mathrm{MOH}$ diagnosis.
\end{abstract}

Keywords: Medication-overuse headache, Migraine, Periaqueductal gray, Magnetic resonance imaging

\section{Background}

Periaqueductal gray (PAG) was an anatomic and functional interface between forebrain and brainstem, and PAG was classified into 4 columns with different cytoarchitecture and included multiple types of neurons (eg. L-glutamate, $\gamma$-aminobutyric acid (GABA), opioids (particularly enkephalin), substance P) [1]. The PAG columns had distinct connections with the forebrain, brainstem, and nociceptive neurons of lamina I of the spinal cord and trigeminal nucleus [2-4]. PAG is a critical component of a network that is activated in response to pain, and the different PAG columns receive functionally segregated input from nociceptive pathways [5-7]. Previous studies demonstrated that PAG activation was modulated by expectation of pain [8] and placebo analgesia [9].

\footnotetext{
*Correspondence: cjr.malin@vip.163.com; yusy1963@126.com

'Department of Radiology, Chinese PLA General Hospital, 28 Fuxing Road, Beijing 100853, China

2Department of Neurology, Chinese PLA General Hospital, 28 Fuxing Road, Beijing 100853, China
}

PAG is a substantial descending pain modulatory center, which exerts a dual control (including inhibition and facilitation) on nociceptive transmission in the dorsal horn and trigeminal nucleus [10], and the modulatory mechanism was exerted by descending PAG-RVM (rostral ventromedial medulla) pathway contributing to central sensitization and development of secondary hyperalgesia [10, 11]. PAG dysfunction was recognized in migraine [12], and functional MRI studies demonstrated that the PAG dysfunction was associated with increased iron deposition, which may play a role in the genesis or pathophysiology of $\mathrm{MOH}$ [13-15].

In the previous studies, the conventional MR imaging demonstrated that specific lesion such as multiple sclerosis and infarction in PAG may produced the migraine-like symptoms [16-21]. and nonspecific lesions without definite clinical diagnosis in PAG region [22]. Voxel-based morphometry (VBM) powerfully demonstrated that the clusters with PAG volume increase in $\mathrm{MOH}$ [23] and the clusters 
with PAG volume reducement in MOH with detoxification treatment response [24]. Therefore, PAG volume changes become an important imaging variable in $\mathrm{MOH}$ for the diagnosis and the treatment assessment.

VBM methods commonly could compare groups of individuals, and it also could be used to compare single case with control groups although a very high false positive rates presents [25] and non-parametric statistics could addressing the problem of high false positive rate in single case VBM [26]. As these methods were performed over the whole brain level, an automated individual PAG volume measurement was applied to $\mathrm{MOH}$ patients in the current study, and the expected cut-off value of PAG volume would be provided for the $\mathrm{MOH}$ diagnosis.

\section{Methods}

\section{Subjects}

Written informed consent was obtained from all participants according to the approval of the ethics committee of the local institutional review board. Twenty-two $\mathrm{MOH}$ patients were recruited from the International Headache Center, Department of Neurology, Chinese PLA General Hospital. All the following inclusion criteria should be fulfilled: 1) diagnosis of $8.2 \mathrm{MOH}$, and 1.1 and 1.2 migraine based on the International Classification of Headache Disorders, third Edition (beta version) (ICHDIII beta) [27]; 2) no migraine preventive medication used in the past 3 months; 3 ) age between 20 and 60 years; 4 ) right-handed; 5) patient's willingness to engage in the study. The exclusion criteria were the following: 1) with any chronic disorders, including hypertension, hypercholesterolemia, diabetes mellitus, cardiovascular diseases, cerebrovascular disorders, neoplastic diseases, infectious diseases, connective tissue diseases, other subtypes of headache, chronic pain other than headache, severe anxiety or depression preceding the onset of headache, psychiatric diseases, etc.; 2) with alcohol, nicotine, or other substance abuse; 3) with cranium trauma, illness interfering with central nervous system function, psychotic disorder, and regular use of a psychoactive or hormone medication. Twenty-two normal controls (NCs) were recruited from the hospital's staff and their relatives. Inclusion criteria were similar to those of patients, except for the first two items. NCs should never have had any primary headache disorders or other types of headache in the past year. General demographic and headache information were registered and evaluated in our headache database. Additionally, we evaluated anxiety, depression, and cognitive function of all the participants by using the Hamilton Anxiety Scale (HAMA) [28], the Hamilton Depression Scale (HAMD) [29], and the Montreal Cognitive Assessment (MoCA) Beijing Version (www.mocatest.org). The study protocol was approved by the Ethical Committee of Chinese PLA General Hospital and complied with the Declaration of Helsinki. Informed consent was obtained from all participants before the study. MRI scans were taken in the interictal stage at least three days after a migraine attack for $\mathrm{MOH}$ patients. All the patients were given with the Visual Analogue Scale (VAS). All the subjects were righthanded and underwent conventional MRI examination to exclude the subjects with cerebral infarction, malacia, or occupying lesions. Alcohol, nicotine, caffeine, and other substances were avoided for at least $12 \mathrm{~h}$ before MRI examination.

\section{MRI acquisition}

Images were acquired on a GE 3.0 T MR system (DISCOVERY MR750, GE Healthcare, Milwaukee, WI, USA) and a conventional eight-channel quadrature head coil was used. All subjects were instructed to lie in a supine position, and formed padding was used to limit head movement. A three-dimensional T1weighted fast spoiled gradient recalled echo (3D T1FSPGR) sequence generating 180 contiguous axial slices [TR $($ repetition time $)=6.3 \mathrm{~ms}$, TE $($ echo time $)=2.8 \mathrm{~ms}$, flip angle $=15 \mathrm{o}$, FOV (field of view) $=25.6 \mathrm{~cm} \times 25.6 \mathrm{~cm}$, Matrix $=256 \times 256$, NEX (number of acquisition) $=1$ ] was used to perform the new segment and the individual PAG creation. Conventional T2-weighted imaging (T2WI) and T1 fluid-attenuated inversion recovery (T1-FLAIR) weighted imaging were also acquired. All imaging protocols were identical for all subjects. No obvious structural damage and T2-visible lesion were observed based on the conventional MR images.

\section{MR image processing}

All MR structural image data were processed using Statistical Parametric Mapping 12 (SPM 12) (http:// www.fil.ion.ucl.ac.uk/spm/) running under MATLAB 7.6 (The Mathworks, Natick, MA, USA) to perform segment [30]. The image processing included following steps: (1) Create PAG template based on mni_icbm152_gm tal_nlin_asym_09a template by pen tool using MRIcron software (www.mricro.com); (2) Individual PAG segment by apply the deformation field (generated by segment) to the PAG template using the runback strategy; (3) calculate the individual PAG volume using ITK-SNAP (V3.6.0-beta) (http://www.itksnap.org/pmwiki/pmwiki.php) (Fig. 1).

\section{Statistical analysis}

The statistical analysis was performed by using PASW Statistics 18.0. The significance differences of PAG volume between $\mathrm{MOH}$ group and $\mathrm{NC}$ group were computed using general linear model (independent univariate $t$-test with age and sex as covariates). The Pearson's correlation analysis was applied between PAG volume and the clinical variables in $\mathrm{MOH}$. The age, HAMA, HAMD and MoCA 


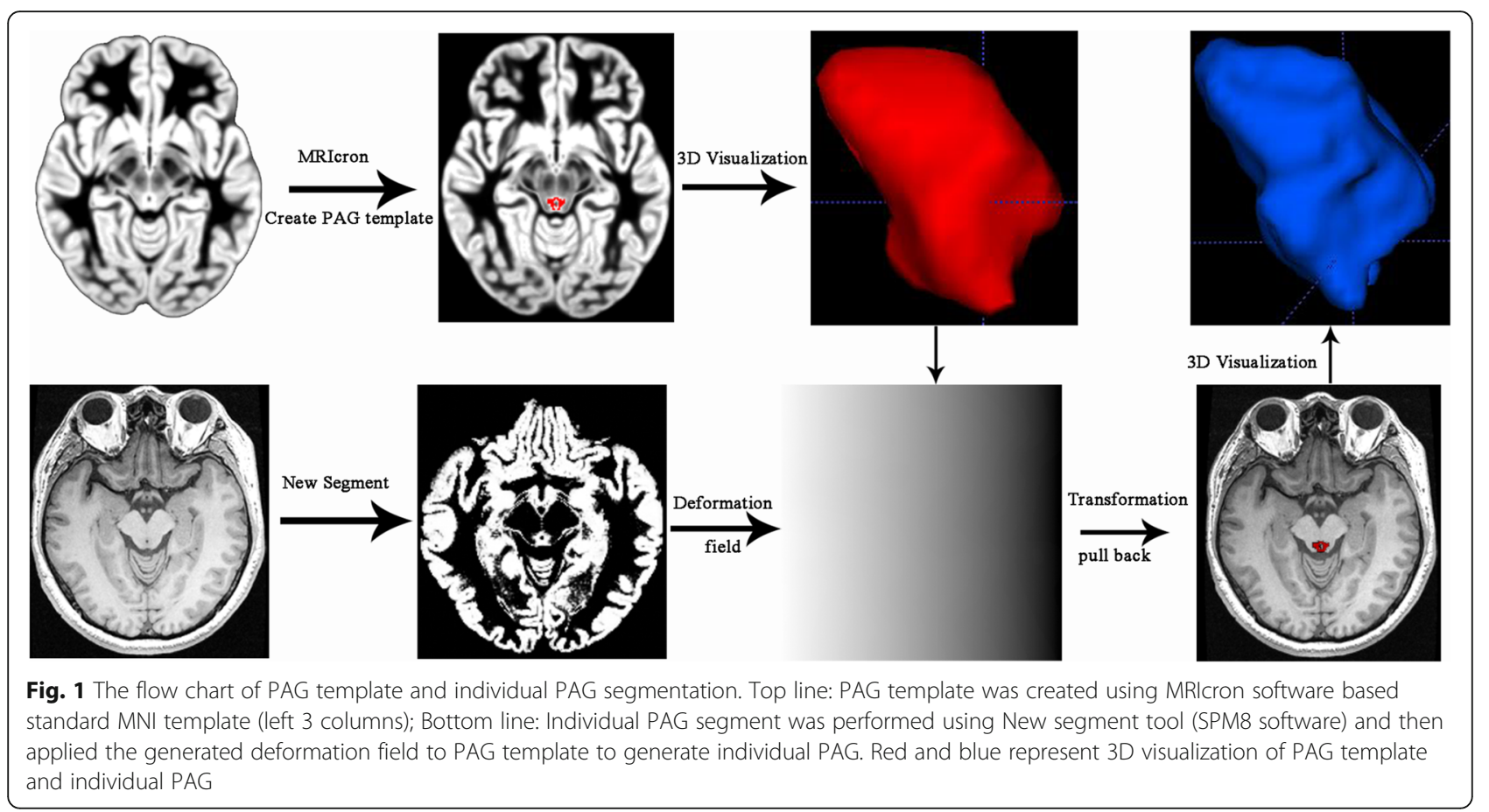

were performed with independent samples $T$ test, and sex was performed with Chi-Square test. Significant difference was set at a $P$ value of $<0.05$. Receiver operating characteristic (ROC) curve analysis was performed to identify the diagnostic efficacy and the cut-off value of PAG volume for $\mathrm{MOH}$.

\section{Results}

Demography and neuropsychological test

Twenty-two $\mathrm{MOH}$ patient $(\mathrm{F} / \mathrm{M}=14 / 8)$ and $22 \mathrm{NCs}$ $(\mathrm{F} / \mathrm{M}=14 / 4)$ were enrolled (Table 1$)$. There was no significant difference for age and sex between $\mathrm{MOH}$ $(42.55 \pm 10.31$ years old) and NC $(45.09 \pm 10.50$ years old). There was significant difference for the scores of

Table 1 The clinical characteristics of $\mathrm{MOH}$ patients and normal controls(NC)

\begin{tabular}{lllll}
\hline & $\mathrm{MOH}$ & $\mathrm{NC}$ & T value & $P$ value \\
\hline Num(F/M) & $22(14 / 8)$ & $22(19 / 3)$ & $3.03^{\text {a }}$ & 0.16 \\
Age(yrs) & $42.55 \pm 10.31$ & $45.09 \pm 10.50$ & 0.81 & 0.42 \\
HAMA & $15.82 \pm 6.81$ & $9.77 \pm 3.15$ & 3.78 & 0.00 \\
HAMD & $17.91 \pm 8.88$ & $8.09 \pm 4.80$ & 4.54 & 0.00 \\
MoCA & $24.23 \pm 3.21$ & $27.50 \pm 1.97$ & 4.08 & 0.00 \\
DD(yrs) & $6.65 \pm 8.00$ & $\mathrm{NA}$ & $\mathrm{NA}$ & $\mathrm{NA}$ \\
VAS & $8.27 \pm 1.52$ & $\mathrm{NA}$ & $\mathrm{NA}$ & $\mathrm{NA}$ \\
\hline
\end{tabular}

NA Not available, $D D$ disease duration ${ }^{\mathrm{a}} \mathrm{Chi}$-Square test
HAMA, HAMD and MoCA in $\mathrm{MOH}$ compared with that in NC $(P<0.05)$. The disease duration was $6.65 \pm$ 8.00 years, and the scores of VAS were $8.27 \pm 1.52$. The type of overused medication in $\mathrm{MOH}$ patients included:simple analgesics (3/22), simple triptans $(1 / 22)$, and combination analgesics $(18 / 22)$.

Comparison of PAG volume between $\mathrm{MOH}$ group and NC group

There was a significant increased volume of PAG in $\mathrm{MOH}(0.366 \pm 0.005 \mathrm{ml})$ than that in $\mathrm{NC}(0.341 \pm$ $0.005 \mathrm{ml})(F$ value $=14.41, P$ value $=0.000)($ Fig. 2$)$. There

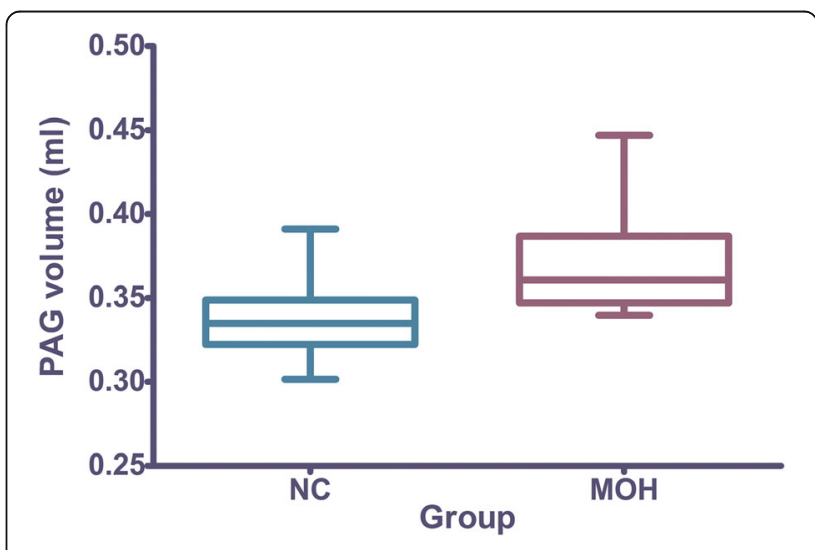

Fig. 2 PAG volume distribution plot of $\mathrm{MOH}$ and $\mathrm{NC}$ 
was no significant correlation between the PAG volume and the clinical variables in $\mathrm{MOH}$ patients $(P>0.05)$.

\section{ROC analysis between $\mathrm{MOH}$ group and NC group}

The area of receiver operating characteristic (ROC) curve was 0.845 , and the cut-off of PAG volume was $0.341 \mathrm{ml}$ with sensitivity $95.5 \%$ and specificity $63.6 \%$ (Fig. 3 ).

\section{Discussion}

PAG dysfunction had been identified in $\mathrm{MOH}$ patients, and the investigation methods including resting-state functional MRI [31-33], diffusion kurtosis imaging [34], positron emission tomography [35], and iron deposition study [13]. The altered PAG function [33] may result in the change of PAG volume. The previous VBM study identified clusters in PAG region with volume increase [36], which was based on normalized grey matter. However, the current study provided the true individual PAG volume change firstly in vivo.

The present findings demonstrated the PAG volume gain in $\mathrm{MOH}$ compared with $\mathrm{NC}$, which may explain the PAG dysfunction in $\mathrm{MOH}$ from the PAG structural pathophysiological change viewpoint. However, the correlation analysis showed that there was no any significant correlation between the PAG volume and the clinical variables in $\mathrm{MOH}$ patients. These findings suggested that PAG volume gain may only be associated with the descending pain modulatory network, and the other clinical factor such as anxiety, depress and cognitive function could not influence the PAG structural change in $\mathrm{MOH}$ although anxiety scores, depression scores showed significant difference between $\mathrm{MOH}$ and NC. The previous study [37] indicated that anxiety and

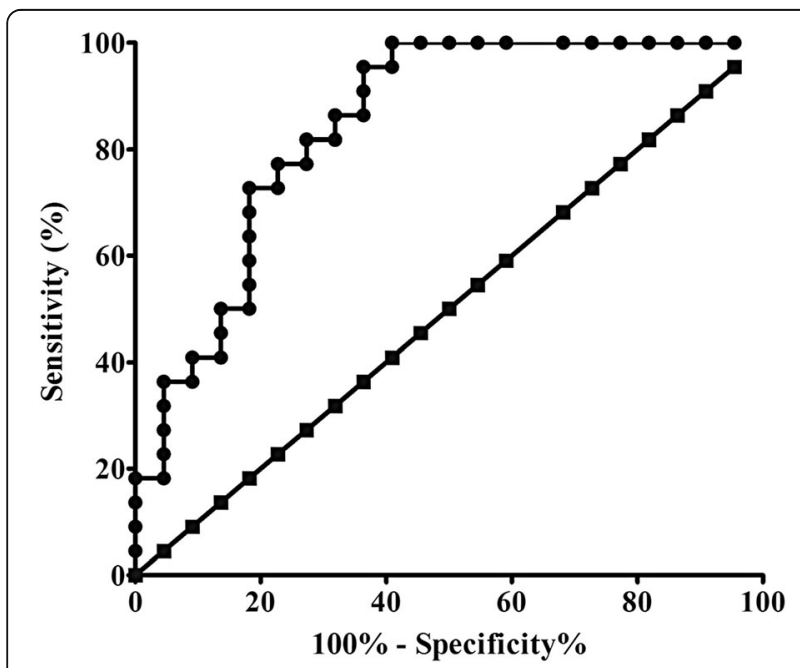

Fig. 3 ROC curve of PAG volume for the diagnosis of $\mathrm{MOH}$ from NC. The area under the curve is 0.845 depression scores was correlated with gray matter volumes of some cerebral regions, therefore, it could assume that anxiety and depression might impair the cerebral regions, and PAG volume gain might be specific change in $\mathrm{MOH}$ patients.

Although PAG volume gain was identified in $\mathrm{MOH}$ in this study, Fig. 2 present a small overlap between $\mathrm{MOH}$ and NC for PAG volume. Further ROC analysis demonstrated PAG volume measurement showed a good level for the diagnosis of $\mathrm{MOH}$ from NC. The cut-off value of PAG volume $(0.341 \mathrm{ml})$ could provide a high sensitivity (95.5\%), however, the specificity (63.6\%) was relative. Therefore, it should be careful to explain the diagnosis of $\mathrm{MOH}$ when PAG volume around the cut-off value.

Compared with VBM study, the current study employed an automated PAG volume measurement. VBM study was generally used to compare the difference between groups, and individual PAG volume could not be measured by this method. In this study, the individual PAG segment was generated by applying the deformation filed to the PAG template, which also be recognized as pull back strategy. This automated PAG measurement method could be performed in the routine clinical practice, and had a widespread application for $\mathrm{MOH}$ diagnosis, even for the treatment response assessment. However, it should be more prudent when PAG volume was considered as a biomarker for the diagnosis of $\mathrm{MOH}$ since $\mathrm{MOH}$ is likely to remain a clinical diagnosis.

The limits for this study included as follows: (1) The sample was relative small, and the large sample of $\mathrm{MOH}$ and $\mathrm{NC}$ should be needed in the future study; (2) The present study was a cross-sectional study, and the longitudinal observation and the treatment response evaluation should further be performed in future study.

\section{Conclusion}

In conclusion, PAG volume gain was identified in $\mathrm{MOH}$ patients, and PAG volume may be considered as an imaging biomarker for the diagnosis of $\mathrm{MOH}$.

Abbreviations

MOH: Medication-overuse headache; NC: Normal controls; PAG: Periaqueductal gray.

\section{Acknowledgments}

This work was supported by the National Natural Sciences Foundation of China (81371514), Special Financial Grant from the China Postdoctoral Science Foundation (2014 T70960) and the Foundation for Medical and health Sci \& Tech innovation Project of Sanya (2016YW37).

\section{Authors' contributions}

Category 1: (a) Conception and Design: L. M; SY. Y. (b) Acquisition of Data: ZY. C; MQ. L; SF. L; XY. C. (c) Analysis and Interpretation of Data: ZY. C. Category 2: (a) Drafting the Article: ZY. C. (b) Revising It for Intellectual Content: L. M; SY. Y. All authors read and approved the final manuscript. 


\section{Competing interests}

The authors declare that they have no competing interests.

Received: 22 November 2016 Accepted: 12 December 2016 Published online: 01 February 2017

\section{References}

1. Benarroch EE (2012) Periaqueductal gray: an interface for behavioral control. Neurology 78:210-7

2. An X, Bandler R, Ongür D, Price JL (1998) Prefrontal cortical projections to longitudinal columns in the midbrain periaqueductal gray in Macaque monkeys. J Comp Neurol 401:455-79

3. Herbert H, Saper CB (1992) Organization of medullary adrenergic and noradrenergic projections to the periaqueductal gray matter in the rat. J Comp Neurol 315:34-52

4. Yezierski RP (1988) Spinomesencephalic tract: projections from the lumbosacral spinal cord of the rat, cat, and monkey. J Comp Neurol 267:131-46

5. Keay KA, Bandler R (2002) Distinct central representations of inescapable and escapable pain: observations and speculation. Exp Physiol 87:275-9

6. Parry DM, Macmillan FM, Koutsikou S, Mcmullan S, Lumb BM (2008) Separation of A- versus C-nociceptive inputs into spinal-brainstem circuits. Neuroscience 152:1076-85

7. Lumb BM (2004) Hypothalamic and midbrain circuitry that distinguishes between escapable and inescapable pain. News Physiol Sci 19:22-6

8. Fairhurst M, Wiech K, Dunckley P, Tracey I (2006) Anticipatory brainstem activity predicts neural processing of pain in humans. Eur J Pain 10:S83b-S

9. Wager TD, Scott DJ, Zubieta JK (2007) Placebo effects on human mu-opioid activity during pain. Proc Natl Acad Sci U S A 104:11056-61

10. Heinricher MM, Tavares I, Leith JL, Lumb BM (2009) Descending control of nociception: specificity, recruitment and plasticity. Brain Res Rev 60:214-25

11. Fields H (2004) State-dependent opioid control of pain. Nat Rev Neurosci 5:565-75

12. Raskin $\mathrm{NH}$, Yoshio $\mathrm{H}$, Sharon $\mathrm{L}$ (1987) Headache may arise from perturbation of brain. Headache 27:416-20

13. Welch KM, Nagesh V, Aurora SK, Gelman N (2001) Periaqueductal gray matter dysfunction in migraine: cause or the burden of illness? Headache 41:629-37

14. Kruit MC, Launer LJ, Overbosch J, van Buchem MA, Ferrari MD (2009) Iron accumulation in deep brain nuclei in migraine: a population-based magnetic resonance imaging study. Cephalalgia 29:351-9

15. Tepper SJ, Lowe MJ, Beall E, Phillips MD, Liu K, Stillman MJ et al (2012) Iron deposition in pain-regulatory nuclei in episodic migraine and chronic daily headache by MRI. Headache 52:236-43

16. Gee JR, Chang J, Dublin AB, Vijayan N (2005) The association of brainstem lesions with migraine-like headache: an imaging study of multiple sclerosis. Headache 45:670-7

17. Haas DC, Kent PF, Friedman DI (1993) Headache caused by a single lesion of multiple sclerosis in the periaqueductal gray area. Headache 33:452-5

18. Lin GY, Wang CW, Chiang TT, Peng GS, Yang FC (2013) Multiple sclerosis presenting initially with a worsening of migraine symptoms. J Headache Pain 14:70

19. Tortorella P, Rocca MA, Colombo B, Annovazzi P, Comi G, Filippi M (2006) Assessment of MRI abnormalities of the brainstem from patients with migraine and multiple sclerosis. J Neurol Sci 244:137-41

20. Fragoso YD, Brooks JB (2007) Two cases of lesions in brainstem in multiple sclerosis and refractory migraine. Headache 47:852-4

21. Wang Y, Wang XS (2013) Migraine-like headache from an infarction in the periaqueductal gray area of the midbrain. Pain Med 14:948-9

22. Chen Z, Chen X, Liu M, Liu S, Ma L, Yu S (2016) Nonspecific periaqueducta gray lesions on $T 2 W I$ in episodic migraine. J Headache Pain 17:101

23. Riederer $F$, Marti $M$, Luechinger $R$, Lanzenberger $R$, von Meyenburg J, Gantenbein AR et al (2012) Grey matter changes associated with medication-overuse headache: correlations with disease related disability and anxiety. World J Biol Psychiatry 13:517-25

24. Riederer F, Gantenbein AR, Marti M, Luechinger R, Kollias S, Sandor PS (2013) Decrease of gray matter volume in the midbrain is associated with treatment response in medication-overuse headache: possible influence of orbitofrontal cortex. J Neurosci 33:15343-9

25. Scarpazza C, Sartori G, De Simone MS, Mechelli A (2013) When the single matters more than the group: very high false positive rates in single case Voxel Based Morphometry. Neuroimage 70:175-88
26. Scarpazza C, Nichols TE, Seramondi D, Maumet C, Sartori G, Mechelli A (2016) When the Single Matters more than the Group (II): Addressing the Problem of High False Positive Rates in Single Case Voxel Based Morphometry Using Non-parametric Statistics. Front Neurosci 10:6

27. Headache Classification Committee of the International Headache Society (IHS) (2013) The International Classification of Headache Disorders, 3rd edition (beta version). Cephalalgia 33:629-808

28. Maier W, Buller R, Philipp M, Heuser I (1988) The Hamilton Anxiety Scale: reliability, validity and sensitivity to change in anxiety and depressive disorders. J Affect Disord 14:61-8

29. Hamilton M (1967) Development of a rating scale for primary depressive illness. Br J Soc Clin Psychol 6:278-96

30. Ashburner J, Friston KJ (2000) Voxel-based morphometry-the methods. Neuroimage 11:805-21

31. Schwedt TJ, Larson-Prior L, Coalson RS, Nolan T, Mar S, Ances BM et al (2014) Allodynia and descending pain modulation in migraine: a resting state functional connectivity analysis. Pain Med 15:154-65

32. Schwedt TJ, Schlaggar BL, Mar S, Nolan T, Coalson RS, Nardos B et al (2013) Atypical resting-state functional connectivity of affective pain regions in chronic migraine. Headache 53:737-51

33. Mainero C, Boshyan J, Hadjikhani N (2011) Altered functional MRI resting-state connectivity in periaqueductal gray networks in migraine. Ann Neurol 70:838-45

34. Ito K, Kudo M, Sasaki M, Saito A, Yamashita F, Harada T et al (2016) Detection of changes in the periaqueductal gray matter of patients with episodic migraine using quantitative diffusion kurtosis imaging: preliminary findings. Neuroradiology 58:115-20

35. Maniyar FH, Sprenger T, Schankin C, Goadsby PJ (2014) The origin of nausea in migraine-a PET study. J Headache Pain 15:84

36. Rocca MA, Ceccarelli A, Falini A, Colombo B, Tortorella P, Bernasconi $L$ et al (2006) Brain gray matter changes in migraine patients with T2-visible lesions: a 3-T MRI study. Stroke 37:1765-70

37. Chanraud S, Di Scala G, Dilharreguy B, Schoenen J, Allard M, Radat F (2014) Brain functional connectivity and morphology changes in medication-overuse headache: Clue for dependence-related processes? Cephalalgia 34:605-15

\section{Submit your manuscript to a SpringerOpen ${ }^{\circ}$ journal and benefit from:}

- Convenient online submission

- Rigorous peer review

- Immediate publication on acceptance

- Open access: articles freely available online

- High visibility within the field

- Retaining the copyright to your article

Submit your next manuscript at $>$ springeropen.com 